\title{
The Impact of Family Education Savings on Children's Academic Performance_-An Empirical Research Based on CFPS2018 Data
}

\author{
Yanfei Liu ${ }^{1 *}$, Wenjing Zhang ${ }^{2}$ \\ ${ }^{1}$ Institute of Political Science and Law, University of Jinan, Jinan, Shandong 250022, China \\ ${ }^{2}$ Research Office, Women's Development Research Center of Shandong Province, Jinan, Shandong 250001, China \\ ${ }^{*}$ Corresponding author. Email: 441684948@qq.com
}

\begin{abstract}
Since the reform and opening up, the contradiction between people's desire to receive education and their actual ability to pay has become more and more prominent. This paper uses the 2018 Family Tracking Survey data to explore the impact of family education savings on children's academic performance in China. The study found that the family education savings have a significant impact on children's academic performance. Under the same conditions, compared with the family without education savings, the children's academic performance in the family with education savings will be relatively high. Because academic performance is an important embodiment of children's educational achievement, the impact of family education savings on the quality of education should not be ignored.
\end{abstract}

Keywords: Education savings, children, academic performance, quality of education

\section{INTRODUCTION}

In modern society, the establishment of family education savings not only means that parents have higher educational expectations for children, but also means that parents have higher ability to resist financial risks, which can provide economic support for children to enjoy equal educational opportunities. Empirical studies show that educational savings have a significant impact on children's academic performance. The famous "Assets and the Poor" points out that educational savings plans can have a significant impact on academic achievement by changing people's perceptions of life opportunities and connecting them to a viable and promising future.[1] Other studies have found that asset-based child development accounts in countries such as the United States, Canada and Singapore work well, and the logic is that over time, increased savings can significantly affect children's academic performance, cognition and behaviour.[2] In summary, children who hold an education savings account achieve better academic performance than those who do not, and educational savings have a positive effect on academic achievement. The potential impact of family education savings on the improvement of educational quality and educational equity should not be ignored.

Although the Chinese family education savings and its influencing factors have been paid attention to by the academic circles, the current situation of holding family education savings and its possible effects have not been thoroughly discussed and verified in the domestic sociology, education and related fields. We still lack a systematic understanding of the impact of Chinese family education savings on children's academic performance. This paper uses CFPS2018 data to explore and test the impact of domestic education savings on children. On the one hand, academic performance has been proved to be an effective and stable indicator for predicting educational outcomes and learning ability, and differences in academic performance can reflect differences in educational outcomes to some extent. On the other hand, since the mid-1990s, with the rapid expansion of Chinese higher education, the cost of higher education has been rising year by year and the educational requirements for employment have been improving, which have attracted the attention of all sectors of the society and may affect the educational investment decisions of families and the academic performance of children.[3] In this context, the study of children's academic performance has important practical significance.

\section{LITERATURE REVIEW}

\subsection{Family Education Savings and Its Background of Creation}

Educational savings are commonly defined as specific deposit in many literature papers. This deposit is deposited in a state-designated bank or other financial institution by the individual, and is made for the purpose of education for himself or others at present or in the future. The principal or interest of the deposit can be used to pay for the educatees' education expenses.[4]

Chinese huge population base determines its potential education demand is very big, education consumption has 
become public seller's markets. However, in recent years, with the widening gap between the rich and the poor and the sharp increase in college tuition, it is very difficult for the general working-class and rural families to provide educational expense for their children. The cost of higher education has increasingly become a heavy economic burden for a large number of middle and low-income families. People's desire to receive education and the actual ability to pay have produced a contradiction, and the problem is increasingly prominent.

In this context, to ease the heavy burden of high tuition on parents and keep more students from being locked out of higher education, the education savings policy emerged in line with the trend of the times and gradually became known to the public.

\subsection{The Impact of Family Education Savings: Empirical Findings and Theoretical Explanations}

In recent years, the impact of education savings on children's education has increasingly become a hot topic of research. Many empirical studies at home and abroad have discussed the relationship between family education savings and children's academic performance. A series of studies on the influence of education savings have been carried out in foreign countries and many valuable research results have been obtained. Research proves that assets have an independent effect on children's academic performance after controlling for parental income and educational expectations. Assets have an independent impact on children's academic performance. For example, the scholar Elliott used the data of the impact of cross-sectional family asset construction on children's academic performance to find that there is a significant positive relationship between family education savings and their math performance. In other words, the more family education savings, the better their math performance.[5]

Domestic achievement papers on education savings mostly focus on descriptive studies on related policies, functions and problems of education savings, as well as the comparison between them and similar concepts. Only in recent years has there been a quantitative study on the impact of education savings on the empirical analysis, but due to the small amount, it is still a weak area of research. For example, when Fang Shu and Su Miaomiao controlled for variables such as gender, age, household registration type and parents' educational expectations, using the data of China Family Panel Studies in 2016, they found that family education savings has a positive effect on the improvement of children's Chinese and math performance. And compared with other asset types, family education savings has more significant influence on children's academic performance.[6]

This welfare effect of education savings can be explained by Sherraden's theory of asset building. According to this theory, the academic performance of teenagers is closely related to their asset holdings. Assets can create a future orientation, a cognitive reality and a schema, meanwhile have an impact on the educational expectations, cognitive development and academic achievement of adolescents.[7] At the individual level, children with education savings have better educational outcomes, including academic performance, high school graduation rates and college enrollment rates, than children without education savings. Because these children have better developmental opportunities and higher educational expectations. Therefore, family education savings have a positive impact on children's educational outcomes. In a family with more assets, children are more likely to have a good environment for socialization. In this case, assets become a booster of education, which is more beneficial to children's access to education. On the contrary, in economically resource-poor families, children are more likely to face cultural and structural barriers, which negatively affecting individual educational outcomes. Based on literature and case studies, Sherraden points out that there is a strong link between educational savings plans and the academic performance of adolescents.

\subsection{Research Comment}

According to the literature review, there have been relevant empirical studies on the cognitive level and influencing factors of family education savings, and family education savings as a part of assets has been proved to have a positive impact on children's math and Chinese performance. However, there is no descriptive study on the ownership of family education savings in the existing literature, and the group differences in the effect of family education savings have not been explored. There are still some weaknesses in the domestic research on the impact of education savings. Therefore, it is of great academic value to clarify the status quo of holding educational savings in China, analyze the impact of educational savings on children's academic performance, and explore the differences in the impact of educational savings between different groups.

\section{RESEARCH HYPOTHESIS}

As for the relationship between China's education savings policy and the revitalization of the education cause, the existing domestic studies mainly discuss the influence of the school-running mode of "education savings fund" and the child development account on China's education cause at the overall level, there are few studies in China to examine the effect of these systems and policies on children's educational outcomes at the micro level. We believe that institutions and policies affect individual educational outcomes through the establishment of Education Savings Account. That is to say, family educational savings is an influencing factor of individual educational outcomes. Therefore, examining the impact of family educational savings on children's academic 
performance can provide a more direct empirical basis for assessing the current educational savings system and policy consequences. Academic performance is the main embodiment of educational outcomes. It is of great practical significance to discuss children's academic performance in China at present. This study focuses on the influence of family education savings on children's academic performance.

According to the asset construction theory and the empirical research at home and abroad, it is found that family education savings has a significant effect on children's academic performance. That is to say, under the same conditions, compared with children without education savings, children with education savings will have relatively high math and reading performance. Foreign studies have confirmed this view,[8] but there are few domestic studies to prove this view. In view of the general rule of the education process, we expect a similar situation existing in China, so we propose the following hypothesis:

Hypothesis 1a: Children from families with education savings have better Chinese performance than those without educational savings.

Hypothesis 1b: Children from families with educational savings perform better in math than those without educational savings.

\section{DATA, VARIABLE AND METHODS}

\subsection{Data}

The data are from China Family Panel Studies(CFPS), funded by Peking University and the Nationl Natural Science Foundation of China. The CFPS is maintained by the Institute of Social Science Survey of Peking University. In the CFPS, all baseline family members and their future blood/adopted children defined by the 2010 baseline survey were permanently tracked as genetic members. The survey takes administrative division and socioeconomic level as the main stratified variables, and adopts probability sampling which is implicit stratified, multi-stage, multi-level and proportioned to population, and selects randomly 25 provinces/cities/autonomous regions representing $95 \%$ of China's population from all over the country. In the 2018 Family Tracking Survey data, there were 14,241 households, 32,669 adults and 8,454 children.[9] The CFPS collects basic information of the children under investigation, acedemic grades, educational savings, and the data from parents and other family members. In general, the data is suitable for answering the research questions in this paper.

\subsection{Variable}

\subsubsection{Dependent variable}

The dependent variable of this study is the academic performance of children at school. We use two indicators to measure academic performance. The first is the children's Chinese performance in school, the corresponding question in CFPS is "as far as you know, which level is the child's usual Chinese performance in the last semester?", the option settings are excellent, good, medium and poor. Second, the children's math performance in school, the corresponding question in CFPS is "as far as you know, which level is the children's usual Chinese performance last semester?", the option settings are excellent, good, medium and poor. In this paper, the value of "poor" is 1 , "medium" is 2 , "good" is 3 , and "excellent" is 4 . The higher the value is, the better the children's academic performance will be. After the assignment, we get two ordination variables with values between 1 and 4 .

\subsubsection{Independent variable}

The purpose of this study is to investigate the impact of family education savings on children's academic performance. The core independent variable is family education savings, and the variable "whether there is education savings" is used to measure family education savings. "whether there is education savings" is a binary variable. The corresponding question is "has your family started saving money for your children's education?", and the answer is encoded as "yes $=1$, no $=0$ ".

\subsubsection{Control variable}

In addition to basic demographic variables such as age, gender, household registration and minority, control variables also include educational expectations, which have been documented to have a significant impact on academic performance. The educational expectations variable is measured by parents' educational expectations and corresponds to the question "which degree do you want your children to finish at least?". According to the design of CFPS, the choices are coded as follows: $0=$ no need to study, 6=primary school, 9=junior high school, $12=$ high school, 15=junior college, 16=bachelor degree, $19=$ master degree, $22=$ doctor degree.

Descriptive statistics for all variables used in this article are shown in table 1 
Table 1 Descriptive statistics of variables

\begin{tabular}{|c|c|c|c|c|c|}
\hline Variable & Variable assignment & Mean & Std.Dev. & Min & Max \\
\hline Chinese performance & 1=poor, $2=$ medium, $3=$ good, $4=$ excellent & 2.754 & 0.984 & 1 & 4 \\
\hline Math performance & $1=$ poor, $2=$ medium, $3=$ good, $4=$ excellen & 2.768 & 1.045 & 1 & 4 \\
\hline Education savings & $1=$ yes, $0=$ no & 0.147 & 0.355 & 0 & 1 \\
\hline Household_registration & $1=$ urban, $0=$ rural & 0.433 & 0.496 & 0 & 1 \\
\hline Age & & 10.886 & 2.567 & 1 & 16 \\
\hline Gender & $1=$ man, $0=$ woman & 0.537 & 0.499 & 0 & 1 \\
\hline Minority & $1=$ yes, $0=$ no & 0.311 & 0.466 & 0 & 1 \\
\hline $\begin{array}{c}\text { Parents'educational } \\
\text { expectations }\end{array}$ & $\begin{array}{l}0=\text { no need to study, } 6=\text { primary school, } \\
9=\text { junior high school, } 12=\text { high school, } \\
15=\text { junior college, } 16=\text { undergraduate } \\
\text { college, } 19=\text { postgraduate, } 22=\text { doctor }\end{array}$ & 15.798 & 2.382 & 6 & 22 \\
\hline
\end{tabular}

\subsection{Analysis Steps and Research Methods}

The data analysis section used multiple regression analysis to estimate the impact of family education savings on children's academic performance. As the Chinese and math performance in the dependent variables are both divided into four grades of "poor", "medium", "good" and "excellent", and are coded as "poor" $=1$, "medium"=2, "good" $=3$, and "excellent" $=4$, which are ordinal variables, the Ordered Logistic Model is used for statistical estimation.

By testing the parallel assumptions of the model, the results met the preconditions for the use of the model, so the Ordered Logistic Model was used to study the impact of education savings on children's academic performance.

\subsection{The Impact of Education Savings on Chinese Performance}

The influence of educational savings on children's academic performance was investigated by regression model. According to whether families set up educational savings for children, Ordered Logistic Model was used to estimate. In terms of specific modeling strategies, the net effect of education savings on academic performance was investigated by adding variables to the model step by step. Table 2 reports the results of the model estimates. Model 1 included the regression results of the control variables, and model 2 included the variables of whether to save money for education. From the perspective of the value of $\mathrm{P}$, both models have passed the statistical test.

\section{RESULTS OF DATA ANALYSIS}

Table 2 The Ordered Logistic Model for estimating the impact of Chinese performance

\begin{tabular}{ccc}
\hline Variable & Model 1 & Model 2 \\
\hline Control variable & & $0.134 *$ \\
Household registration & $0.150^{* * *}$ & $(0.057)$ \\
Age & $(0.057)$ & $-0.097 * * * 098 * * *$
\end{tabular}


Gender

$-0.532 * * *$

Minority

$0.127 * * *$

Parents'educational

expectations

Dependent variable

Education savings

/cut1

/cut2

/cut3

4186

$\mathrm{n}$
$-0.538 * * *$

$0.123 * * *$

0

Annotation: $+\mathrm{p}<0.1,{ }^{*} \mathrm{p}<0.05, * * \mathrm{p}<0.01, * * * \mathrm{p}<0.001$ (two-tailed test); the numbers in brackets are standard errors.

Model 1 in table 2 is a baseline model that estimates the impact of demographic variables and parental educational expectations on children's Chinese performance. It can be found that the coefficients of age, gender and parents' expectational educations are all significant at the level of 0.001 , the coefficients of household registration are significant at the level of 0.01 , and minority does not affect children's Chinese performance. After controlling for other factors, the Chinese performance of urban children were higher than those of rural children; the older the children, the lower their Chinese performance; girls scored higher in Chinese performance than boys; the higher the parents' expectational educations, the better the children's Chinese performance.

Model 2 adds a core independent variable on the basis of model 1: whether there is education savings. The coefficient of this variable was $0.288(\mathrm{p}<0.001)$, indicating that the establishment of educational savings could improve children's Chinese performance. To be specific, other factors remaining unchanged, children with education savings were about $33.4 \%$ more likely to improve their Chinese performance than children without education savings (e0.288-1 $\approx 0.334)$. In conclusion, the estimated results of model 2 show that after controlling for demographic variables and parents' educational expectations, family education savings has a significant effect on children's Chinese performance. Compared with families without education savings, children from families with education savings have better Chinese performance. The above results validate hypothesis 1a.

\subsection{The Impact of Education Savings on Math Performance}

In order to test the robustness of the statistical results, the dependent variables of all models in table 2 were replaced by children's math performance at school. The Ordered Logistic Model was used for the estimation, and the results are shown in table 3. 
Table 3 The Ordered Logistic Model for estimating the impact of math performance

\begin{tabular}{|c|c|c|}
\hline Variable & Model 1 & Model 2 \\
\hline \multicolumn{3}{|l|}{ Control variable } \\
\hline \multirow[t]{2}{*}{ Household registration } & $0.297 * * *$ & $0.280 * * *$ \\
\hline & $(0.057)$ & $(0.058)$ \\
\hline \multirow[t]{2}{*}{ Age } & $-0.166 * * *$ & $-0.168 * * *$ \\
\hline & $(0.011)$ & $(0.011)$ \\
\hline \multirow[t]{2}{*}{ Gender } & -0.027 & -0.033 \\
\hline & $(0.057)$ & $(0.057)$ \\
\hline \multirow[t]{2}{*}{ Minority } & 0.033 & 0.032 \\
\hline & $(0.024)$ & $(0.024)$ \\
\hline Parents'educational & $0.153 * * *$ & $0.150 * * *$ \\
\hline expectations & $(0.013)$ & $(0.013)$ \\
\hline \multicolumn{3}{|l|}{ Independent vaarible } \\
\hline \multirow[t]{2}{*}{ Education savings } & & $0.289 * * *$ \\
\hline & & $(0.081)$ \\
\hline \multirow[t]{2}{*}{ /cut1 } & -1.529 & -1.559 \\
\hline & $(0.304)$ & $(0.305)$ \\
\hline \multirow[t]{2}{*}{ /cut2 } & 0.136 & 0.110 \\
\hline & $(0.303)$ & $(0.304)$ \\
\hline \multirow[t]{2}{*}{ /cut3 } & 1.264 & 1.240 \\
\hline & $(0.303)$ & $(0.304)$ \\
\hline $\mathrm{n}$ & 4186 & 4186 \\
\hline Prob $>$ chi 2 & 0 & 0 \\
\hline
\end{tabular}

Annotation: $+\mathrm{p}<0.1, * \mathrm{p}<0.05, * * \mathrm{p}<0.01, * * * \mathrm{p}<0.001$ (two-tailed test); the numbers in brackets are standard errors.

We can see that the overall pattern of the estimated results for all the models in table 3 is exactly the same as in table 2. Model 2 in table 3 shows that the math performance of children with education savings are higher than those of children without education savings. To be specific, all other factors being equal, children with education savings were about $33.5 \%$ more likely to improve their math performance than children without education savings $(\mathrm{e} 0.289-1 \approx 0.335, \mathrm{p}<0.001)$. The results here validate hypothesis $1 \mathrm{~b}$.

In conclusion, the statistical estimation results of the models in table 2 and table 3 show that the differences in children's academic performance not only depend on the type of children's household registration, gender, age and parents' educational expectations, family education savings is also an important factor to explain children's academic performance. The establishment of family education savings can often improve children's academic performance. The above results provide a direct empirical basis for the policy demands of improving children's academic performance.

\section{CONCLUSION}

By using the 2018 Family Tracking Survey data, this paper 
explores the impact of family education savings on children's academic performance. It is found that family education savings have a significant impact on children's academic performance. Controlling other factors remained the same, children who held educational savings did better in academic performance at school.

Education saving is not only a hot topic in academic research, but also one of the core issues in educational policy debate.[10] In developing educational savings, the party and the government have also taken major decisions and measures. For example, in 2005, State Administration of Taxation, the People's Bank of China and Ministry of Education of the People's Republic of China jointly issued the implementation measures for the exemption of individual income tax on interest income from education savings deposits, which made uniform provisions on student identity certificates.[11] It can be seen that the current policy formulation pays more attention to the concrete implementation and refinement of education savings, ignoring the impact of family education savings on educational opportunity equity. Therefore, the policy implication of this study is that if children are given the opportunity to have their own education savings account through reasonable policy interventions, it will help to improve their academic performance. On the social level, reducing the differences in children's learning ability gradually is one of the effective ways to overcome the unfairness of education, promote the equality of opportunities and let children have an upward channel.

There are still shortcomings in this paper. As for the mechanism of action between family education savings and children's academic performance, quantitative or qualitative research data on parent-child interaction are still needed. That is why we should encourage more research and database building, which are based on families and children, to provide solid empirical evidence for formulating policies to develop educational savings.

\section{REFERENCES}

[1] Michael Sherraden, Assets and the Poor:A New American Welfare Policy, Trans, Gao Jianguo, The Commercial Press, Beijing, 2005, pp. 185-189.

[2] Fang Shu, Su Miaomiao, Family Asset Building and Child Welfare development:A Review and Domestic Reflection, Journal of East China University of Science and Technology(Social Science Edition). 34(2) (2019) 28-35. DOI: http://doi.org/CNKI:SUN:H DLS.0.2019-02-006

[3] Wu Yuxiao, Educational Opportunities for Rural and Urban Residents in China, 1978-2008: Inequality and Evolution, Social Sciences in China. 34(3) (2013) 58-75. DOI: https://doi.org/ 10.1080/02529203.2013.820555

[4] Chen Zhonglian, Wu Yingmin, Zhang Shuocheng et al, A Major Measure to Revitalize Education by Financial
Means_-A Study and Suggestion on Education Savings, Academic Research. (6) (1996) 102-107. DOI: http://doi.or g/CNKI:SUN:XSYJ.0.1995-06-022

[5] Elliott, W., Destin, M., \& Friedline, T, Taking stock of ten years of research on the relationship between assets and children's educational outcomes: Implications for theory, policy and intervention, Children and Youth Services Review. 33(11) (2011) 2312-2328. DOI:https://doi.org/10.106/j.childyouth.2011.08

[6] Fang shu, Su miaomiao, The Impact of Family Assets Construction on Children' Academic Performance: An Empirical Analysis Based on CFPS2016 Data, Sociological Review of China. 7(2) (2019) 42-54. DOI: http://doi.org/ CNKI:SUN:SHPL.0.2019-02-004

[7] Michael Sherraden, Assets and the Poor:A New American Welfare Policy, Trans, Gao Jianguo, The Commercial Press, Beijing, 2005, pp. 217-218.

[8] Loke, V., \& Sherraden, M, Building assets from birth: a global comparison of Child Development Account policies, International Journal of Social Welfare. 18(2) (2008) 119-129. DOI: https://doi.org/10.1111/j.1468-2397.2008.0 0605.x

[9] Xie Yu, Hu Jingwei, Zang Chunni, The China family Pany Studies: Design and Practice, Chinese Journal of Sociology. 34(2) (2014) 1-32. DOI: https://doi.org/10.15992/j.cnki.31-1123/c.2 14.02.003

[10] Wu Yuxiao, Huang Chao, School Socioeconomic Segregation and Educational Expectations of Students in China's Junior High Schools, Social Sciences in China. 38(3) (2016) 112-116. DOI: http://doi.org/10.1080/02529203. 2017.1339449

[11] Xu Liping, Zhang Wanpeng, Combing and Reflecting on the Educational Savings Policy in China, Journal of Shanghai Educational Research. (2) (2007) 14-17. DOI: 10.16194/j.cnk i.31-1059/g4.2007.02.005 